САБИРОВА Нагима Садыковна - кандидат политических наук, Московский государственный областной университет (141014, Россия, Московская обл., г. Мытищи, ул. Веры Волошиной, 24; snagima95@gmail.com)

\title{
МОДЕЛЬ ПОЛИТИЧЕСКОЙ КУЛЬТУРЫ СОВРЕМЕННОЙ РОССИИ
}

\begin{abstract}
Аннотация. В статье политическая культура в современной России рассматривается как одна из форм социальной жизни. Автор отмечает, что политическая культура способна себя проявлять при любом политическом режиме: различия заключаются только в тональности политического диапазона - «громко» или «шепотом». Рассматривая политическую культуру современной России в контексте культуры страны в целом, автор подчеркивает необходимость предусматривать не косвенную, а непосредственную ее причастность к культурной политике государства. Как политико-правовой фундамент политическая культура может стать гарантом развития самой культурной политики.

Ключевые слова: политическая культура, централизованное государство, демократия, правовое государство, гражданское общество, традиционные ценности, социальный раскол
\end{abstract}

$\Pi$ олитическая культура - это синтез всеобщей культуры человечества. Политическая культура - это фундаментальная модель поведения, выраженная в отношениях между обществом и государством. Исходя из данной ремарки, следует отметить, что, хотя на сегодняшний день достаточно много работ о политической культуре, в частности, о ее развитии в России, тем не менее поставленная тема не только сохранила к себе интерес, но и имеет определенную специфику - быть актуальной всегда. Это потому, что от ее функциональных механизмов зависит мирное благополучие каждого нового дня. Политическая культура способна проявлять себя при любом политическом режиме; возможно, различия заключаются только в тональности политического диапазона - «громко» или «шепотом».

Таким образом, политическая культура - это часть политико-правовой системы, всецело зависимая от политического режима государства. Под давлением исторических, политических событий, что были пережиты многими странами, в т.ч. и Россией, она подвержена трансформации. Но изначально под удар реформистских перестановок попадает сам режим, что далее отражается на остальных механизмах подвластных ему структур, в т.ч. и на политической культуре, которая усваивает функциональные позиции, отвечающие новым стандартам. Из этого следует, что политическая культура как аспект государственного обустройства складывалась по концепции событийного времени.

Исторический раскол российского цивилизационного организма, по мнению В.А. Носкова, видится в том, что в решающие моменты смены одной парадигмы на другую преобладающее влияние приобретает утилитарная тенденция. Это означает, что воля ключевых акторов этого процесса - власти и общества - оказывается под воздействием установки на то, чтобы «начать новую жизнь». Потому переход от одной политико-культурной парадигмы к другой сопровождается радикальной сменой декодирующего механизма: одно и то же явление получает совершенно разную интерпретацию, знак плюс меняется на минус и наоборот [Носков 2005: 107]. Происходит обновление всех ключевых механизмов общественной жизни. Парадокс в том, что политическая культура представляет собой довольно сложную конструкцию: она зависима как от го- 
сударственных рычагов, так и не менее от своего носителя - индивида; именно он - катализатор ее жизни.

По Г. Алмонду и М. Веберу, власть представляет собой способность или возможность производить желаемое воздействие на поведение того или иного объекта, что предполагает наличие активного субъекта, который влияет на объект какими-либо физическими (материальными) или идеальными (духовными) методами. Политическая субъектность - сознательное и активное участие социальных единиц формирования социально-политических действий.

Основные признаки субъектности: возможность принятия политических решений; способность влиять на принятие политических решений; наличие необходимых средств для реализации решений ${ }^{1}$.

Реальность видится в том, что при хорошем раскладе политическая культура должна отождествляться в каждом индивиде. В этом случае он должен получить определенные условия. Они кроются в признании и защите подлинных прав и свобод человека и гражданина вне зависимости от его социального статуса и занимаемой должности. К сожалению, все попытки либеральной власти изменить жизнь малоимущих граждан в лучшую сторону пока не достигли большого успеха, проблема бедности так и остается нерешенной. Лечение в дорогостоящей клинике, возможность при юридических спорах нанять адвоката, оплатить качественное образование сына или дочери, купить путевку в санаторий, приобрести собственное жилье - по сути, обычные жизненные блага - многим гражданам не по карману. Очевидно, эти серьезные проблемы могут стать преградой для дальнейшего развития политической культуры в России.

А.Т. Кочетков предлагает обратить внимание на утвердившийся опыт западных стран, который показал, что там, стремясь избежать обострения общественных противоречий, государство берет на себя функцию распределения прибыли через систему налогов, поощряет создание страховых и благотворительных фондов и т.д. Одновременно государство устанавливает более высокий процент, идущий из прибыли в фонд заработной платы работников [Кочетков 1992: 19].

Однако внутренние социальные проблемы в нашей стране, напрямую влияющие на политическую культуру, не являются следствием того, что российским гражданам безразличны цели, поставленные верховной властью. Следует подчеркнуть, что большая часть россиян политизированы, не равнодушны к своему Отечеству, что не может не радовать.

Итак, в чем же заключаются государственные цели в области политической культуры? Более подробно их раскрывает В.С. Нерсесянц. Он пишет, что политическая идея современной России ясна: развивать политическую культуру в ядре гражданского общества и правового государства. Также он указывает проблему, которая мешает реализации поставленных задач: существование гражданского общества невозможно без качественного изменения самого человеческого материала - превращения индивидов в граждан, имеющих равные гражданские права и соответствующие гражданские качества [Нерсесянц 1997: 106]. Цели двадцатилетней давности и сегодня не утратили своей актуальности. Правовое государство, гражданское общество, политическая культура это звенья одной цепи в современной России, которые продолжают формироваться. Как замечено автором, «превращение индивидов в граждан» требует развития гражданских качеств, возлагаемого на все структуры жизнедеятель-

1 Индивид как первичный субъект политики. Классификация политических индивидов по Г. Алмонду, М. Веберу. - Инфопедия. Доступ: https://infopedia.su/17x357e.html (проверено $06.11 .2020)$. 
ности общества, что ускорит преодоление препятствий на пути к демократическим принципам жизни. Разумеется, успех зависит не только от ключевых механизмов, но и - даже более - от личностных восприятий. И здесь неизбежно столкновение с иными интерпретациями. По сути, демократия - это когда внутри демократического союза допустимы другие идеалы, не совсем близкие самой демократии, и они мирно уживаются. Возможно, это имеет место и в России, и это, наверное, повлекло за собой такое мнение, что современная политическая культура российского общества весьма противоречива, т.к. состоит из множества субкультур - демократических, консервативных, элитарных, массовых и т.д. Каждая субкультура принадлежит определенной социальной группе. Как бы то ни было, в идеале их должны объединить общие ценности, защищающие жизнь, права и интересы граждан. В настоящее время наблюдается некое размежевание общества на отдельные типы сознания и политической культуры. Приходится признать, что сам внутренний раскол происходит не из-за инфантильности одних, как это было отмечено многими исследователями несколько лет тому назад. Скорее причина кроется в нестыковке точек зрения. Это больше похоже на политическую зрелость населения, которая допускает противоречия из-за несогласия и иного понимания последствий той или иной политической ситуации. Они могут повлиять как на устойчивость традиции, так и на ее изменения. То есть, сам народ желает участвовать в координации политического вектора своего государства. Однозначно и то, что менталитет россиян расположен к консолидации при решении глобальных проблем жизнеутверждающего характера.

Сегодня Россия, как и многие страны, соблюдает режим ограничений в связи с пандемией $C O V I D-19$. По наблюдениям, не обошлось без скептиков, но основная часть россиян отнеслись с большой долей ответственности к принятым мерам. Это не только человеческий и гражданский долг - это определитель высокого уровня политической культуры.

Исследуя аспекты политической культуры современной России, необходимо отметить, что политическая культура - это не только локальная деятельность того или иного ведомства, но совместная деятельность всех причастных к культуре структур по осуществлению единой, взаимосвязанной в своих частях общегосударственной культурной политики. И субъектами формирования такой комплексной культурной политики являются творческие работники, деятели науки, потребители культурных ценностей, а также физические и юридические лица, способные ресурсно поддержать культурную жизнь [Жидков, Соколов 2001: 580].

Есть ощущение, что при всех преобразованиях, случившихся в последние годы, и при внутренней противоречивости самих россиян Россия сумела сохранить свои исторические нравственные устои, что не может не быть фундаментальной ценностью. В разных уголках необъятной России народ, сохранивший вековой дух верности и чести, не только способен отстаивать и определять свою жизнь, но и быть в ответе за жизнь своего Отечества.

Таким образом, государство, которое заинтересовано в политико-культурном развитии своего общества, обязано согласовывать интересы субъектов культурной жизни, обеспечивать определенный баланс объемов предложения культурных услуг и спроса на них со стороны различных социокультурных групп. Анализ попыток реализовать это положение в различных странах показывает, что чаще «центральное правительство делает основной упор на гарантии качества; региональные и местные органы управления больше сконцентрированы на гарантиях доступности местного потребления и участия в культурной жизни» [Марченко 1992: 12]. 
Есть предположение, что, рассматривая политическую культуру современной России, следует предусматривать не косвенную, а непосредственную ее причастность к культурной политике государства. Как политико-правовой фундамент она может стать гарантом развития самой культурной политики и не допустить неограниченного внешнего вмешательства в эту сферу, потому что культура - это саморегулирующаяся сфера общественной жизни, имеющая собственную логику и присущие ей внутренние генетические потенции. В этой сфере большую роль играет правильное соотношение регулирования и саморегулирования. Эти оптимальные пропорции зависят как от вида культурной деятельности, так и от конкретной исторической ситуации [Жидков, Соколов 2012: 80].

Также необходимо обратить внимание на ход российской истории, которая показывает, что здесь чрезвычайно велика роль духовного компонента. Общество тогда способно ставить и решать масштабные задачи в области политики, экономики, культуры, когда у него есть общая система нравственных ориентиров. В основе этой общности - единство многонациональных культур народов России [Ивлиев 2012: 19].

Культурная среда сегодня - главный фактор современного общества; приобщение к ней возможно при надежном способе передачи гражданам страны чувства гражданской идентичности.

Сегодня в политической культуре России наблюдается социально дифференцированное состояние - колебание между моделью традиционной культуры и моделью культурной политики рыночного типа. Отказ от традиционных отечественных идеалов, культурного своеобразия и традиционных ценностей оказывается на поверку средством быстрого доступа к материальным ресурсам модели, облюбованной и предлагаемой непрошенными цивилизаторами страны в обмен на фальшивые ценности гламура, его блестящую мишуру [Ивлиев 2012: 13].

Необходимо сохранить все многообразие культур и традиций, возродить самосознание и при всем этом богатстве не оторваться от передовых технологий, смотреть в будущее, отвечая на глобальные вызовы времени.

Таким образом, следует признать, что России в силу объективных обстоятельств всегда будет не хватать сильного эффективного государства, что не может не отразиться на политической культуре. В государстве, где господствует демократия, власть ограничена гражданами, оплотом которых является гражданское общество. В современной России, согласно аналитическому прогнозу, либеральная политическая культура граждан развивается в единой цепочке с демократией и гражданским обществом; последние служат как бы ее движителем. Чтобы прийти к намеченным целям, за которыми стоят интересы как общества, так и самой власти, необходимо построить между ними прочный взаимный диалог. При этом очевидно, что государственный патернализм в интересах страны обязан создать условия для улучшения социокультурной среды.

За последние годы Россия пережила ряд кардинальных реформ и преобразований, что сказалось и на развитии политической культуры российского общества. Особенное влияние на нее оказали появление новых социальных групп, рост социального неравенства, изменение политических, экономических и духовных основ жизни общества. Эти процессы, которые возникли как бы в интересах демократических процедур, указывают на необходимость более глубокого подхода к рассмотрению реформ важных структур общества. В целом развитие политической культуры России зависит от многих факторов, и прежде всего от решения экономических, политических, социаль- 
ных проблем, которые сейчас стоят очень остро. Тут важно, чтобы реформы согласовывались с реальной жизнью людей и их возможностями. Мотивация новшеств должна иметь целью направление мировоззренческих и поведенческих ориентиров людей в сторону созидания и благополучия. Ситуация с сегодняшней пандемией также неизбежно отразится на уровне политической культуры страны и на дальнейшем ее формировании, которое займет еще много времени.

Старшее поколение россиян не утратило свои ценности, такие как труд, традиции, стабильность в семье, но ориентиры молодежи больше нацелены на быстрые деньги, потребление, сферу досуга, карьеру, отсюда зачастую ее аполитичность. Тем не менее наша молодежь не инфантильна, она остро осознает настоящее и видит свое будущее, способна выражать свои мысли, защищать свои идеи и критиковать, когда ее вводят в заблуждение. Именно новое поколение граждан станет вектором политической культуры России.

\section{Список литературы}

Жидков В.С., Соколов К.Б. 2001. Культурная политика: современный этап. Культурная политика России: теория и история: учебное пособие для вузов. М.: Академический проект; Агентство «Издательский сервис». 592 с.

Жидков В.С., Соколов К.Б. 2012. Средства осуществления государственной культурной политики. - Культурная политика России: теория и история: учебное пособие для вузов. М.: Академический проект; Агентство «Издательский сервис».

Ивлиев Г.Т. 2012. Традиции культуры и уроки кризиса. - Культурная политика и развитие законодательства о культуре в Российской Федерации. М.: Норма-М.

Кочетков А.Т. 1992. О формировании гражданского общества. - Социальнополитические науки. № 1.

Марченко Т. 1992. Социальные гарантии в культуре. - ГБЛ. Информкультура М. ДОР. Сер. I, IV. Вып 5.

Нерсесянц В.С. 1997. Философия права: учебник для вузов. М.: ИНФРА-М; Норма. 647 с.

Носков В.А. 2005. Политико-культурная детерминанта развития общества: герменевтика российской реальности: монография. Белгород: Изд-во БелГУ. $218 \mathrm{c}$.

\section{MODEL OF POLITICAL CULTURE OF MODERN RUSSIA}

\footnotetext{
Abstract. The article considers the political culture in modern Russia as one of the forms of social life. The author notes that political culture is able to manifest itself in any political regime; perhaps the differences are only in the tone of the political range - «loudly» or «in a whisper». Considering the political culture of modern Russia in connection with the culture of the country as a whole, the author emphasizes the need to provide its direct involvement in the cultural policy of the state. As a political and legal foundation, political culture can become a guarantor in ensuring the development of cultural policy itself. Keywords: political culture, centralized state, democracy, legal state, civil society, traditional values, social split
} 